\title{
Implementation of energy management in the industrial sectors
}

\author{
CARINA BEERMANN \\ Faculty of electrical engineering and communication (FEEC) \\ Brno University of Technology \\ Antonínská 548/1, 60190 Brno-střed \\ CZECH REPUBLIC
}

\begin{abstract}
Global climate change, scarce energy resources and the increase in energy consumption make action urgently necessary. For everyday life, suggestions and legal regulations have been created to deal with the scarcity of resources and sustainability. In industry, guidelines and laws regulate the handling of resources such as electrical energy. Controlled energy policy and "voluntary" reduction of energy demand, especially in energy-intensive companies, play a decisive role and offer the approach for a possible resolution of this tension through the application of an energy management system. In order to achieve the goal of efficient energy management, a constant individual review of the systems have to take place, for example with the help of the Plan-Do-Check-Act cycle at short intervals, in order to offer continuous. This paper examines whether the implementation of measures through standards, directives and regulations is sufficient to achieve the timely energy policy goals. Furthermore, it needs to be clarified whether energy management itself needs to be more in focus.
\end{abstract}

Key-Words: - Energy management system, Energy policy, PDCA-Cycle, Renewable energy sources, ISO 50001, Current legal European Acts

Received: December 3, 2020. Revised: July 5, 2021. Accepted: July 8, 2021. Published: July 16, 2021.

\section{Introduction}

This paper presents the requirements for energy management from the perspective of the International Organisation for Standardisation, European Union and the international and current European legal situation. Based on guidelines, studies, regulations, directives and legal texts, the added value of energy management in connection with the PDCA cycle is analysed. The focus of this work is mainly on the implementation of energy management in the industrial sectors. The strategy and procedure for implementation are exemplified by the PDCA cycle. A large part of society is dependent on resources such as electricity, oil, gas, and water. Without these resources, daily life would be inconceivable. First, energy policy goals oblige and encourage industry to operate an energy management system. In the meantime, European law has developed into a very important source of law, because the primacy of application of European law applies to matters relating to the Union or directly affecting Europe. In this context, regulations and directives are of particular interest within the framework of secondary law. Regulations have direct effect for citizens and member states (Art. 288 TFEU). Directives must be transposed into national, Member State law in conformity with the directive by certain deadlines.

In contrast to a regulation, they only specify the objective, but not the means. They are therefore addressed to the member states, 
usually with the requirement to transpose them into national law - laws or regulations. Therefore, the objectives of directives are also reflected in concrete form in national laws. The overriding motivation is to raise awareness in dealing with valuable resources; in the industrial environment as well as in private households. The resource consumption of computing centres, the energy consumption in the manufacturing sector and the communication-capable compact circuit breaker (Siemens 3VA2) is used as an object in the energy distribution system as an example for the implementation of energy management in the industrial environment [1][2].

This paper is organised as follows: section 2 reviews the legal framework for the enforcement of energy efficiency; section 3 proposed an overview of examples how energymanagement is implemented, section 4 is on the result analysis while section 5 is on conclusion and future work.

\section{Legal framework for the en- forcement of energy efficiency}

2.1 Current European legal acts

To implement the Paris Climate Agreement of 2015, the European Commission presented its legislative package "Clean Energy for All Europeans" on 31 November 2016 as the so-called "Winter Package" with new climate and energy policy targets for the period after 2020 and the framework for the implementation of the Energy Union until 2030 [3].

The three main objectives of this "winter package" are firstly to reduce greenhouse gas emissions by at least $40 \%$ compared to 1990 , secondly to increase the share of renewable energy sources to at least $32 \%$ of final energy consumption, and thirdly to increase energy efficiency by reducing primary energy consumption by at least 32.5 $\%$ compared to the reference scenario (1990) [3]. In the meantime, the European Parliament has adopted the amendments to the Renewable Energy Directive (EERL II) [1], the Energy Efficiency Directive (EED) [5], as well as the Regulation on the Governance of the Energy Union [6]. The revised Energy Efficiency Directive, which is of particular interest here, provides for a reduction of primary energy consumption within the European Union by $32.5 \%$ by 2030 compared to an underlying reference development (Art. 1 I EED). The central implementation element, the "final energy savings obligation", was extended and strengthened beyond 2020. For the first time, annual real savings of $0.8 \%$ of energy sales in each Member State were agreed (Art. 7 I EED).

\subsection{Energy management according to ISO 50001 in connection with the PDCA-Cycle Subsection}

Every company can decide how it wants to organize its energy management, but it must adhere to the requirements of ISO 50001 to ensure that subsequent certification is successful. ISO 50001 is a globally valid standard for the implementation of an energy management system and contains measures to increase the energy efficiency of companies. It describes many criteria, the realization of which can lead to high energy savings potentials and thus reduce costs, but also reduce the influence on the environment.

The ISO certification according to ISO 50001:2011-12 is valid for a period of three years but have to be verified by annual audits. The aim is to monitor compliance with the defined indicators, but also the implementation of further energy saving measures, and to ensure a continuous process, which is a strategic task of the management level of a company. If a company decides to be certified according to ISO 50001, it has entered a so-called PDCA cycle. This includes the several areas like Plan, Do, Check and Act and have to be carried out annually. It is derived from ISO 50004 (2014-12): Energy management sys- 
tems - Guidance for implementing, maintaining, and improving an energy management system. In this way, continuous optimisation and a permanent reduction in energy consumption are to be achieved. After three years, a renewed certification have to take place as a recertification. For the implementation of an energy management system, an energy assessment of the company/organisation has to be first take place. Therefore, a collection of all relevant data must be carried out by the respective persons in charge beforehand. This data includes, among other things, information on past and current energy use and energy consumption and on the factors that influence energy consumption. Facts about current energy efficiency should also be collected. In a threestage analysis, energy consumption and energy use are presented in de-tail, the areas with the highest consumption are identified, and subsequently possibilities for permanent improvement of the energy balance as well as operational goals are determined ("Plan" in PDCA cycle). Once the planning has been completed, the next step is to implement the defined measures ("Do" in the PDCA cycle). In any case, the employees should be involved in the implementation of the measures at this point at the latest. They work in the respective areas on a daily basis and can often provide additional information on further savings opportunities.

Then those responsible, monitor the measures taken and the achievement of the goals ("Check" in the PDCA cycle). For example, the current energy consumption is measured and this data is aligned with the targets. Realtime data is a profitable means of drawing timely conclusions and making comparisons. In addition, internal audits have to be carried out regularly so that system conformity can be checked and any corrections can be initiated. The documentation of the data should be transparent so that it is available in the desired form for future certification. By monitoring the processes, possible changes are possible, which can or have to be made by those responsible for the process, i.e. the management level ("Act" in

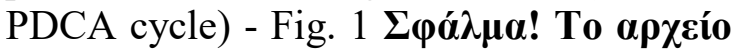

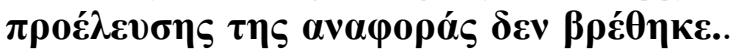
The management review is also particularly important as a strategic task, because the responsible management is responsible for monitoring all measures introduced so far and for checking their effectiveness. If necessary, this process can be followed by further measures to improve the energy balance or new goals can be decided upon. For this purpose, special action plans are drawn up that build on each other.

\subsection{Objectives of the European Union}

Based on the EU's strategic goals up to the year 2030 till 20th april 2021 [6]:

- Reduction of greenhouse gas emissions by $40 \%$ compared to 1990 .

- Increase the share of renewable energy sources to at least $32 \%$ of final energy consumption.

- Reduction of primary energy consumption by at least $32.5 \%$ compared to 2007.

This challenge of 2030 as an intermediate target and 2050 as the relevant horizon means a change in our way of life and economy. In order to achieve the reduction targets of the European Union (EU) for large emitters from the industry and energy sectors as well as EU aviation together, an emissions trading system (ETS) was established in the EU as early as 2005.

The reduction of greenhouse gas emissions in the remaining sectors of transport, buildings, industry (as far as not part of the ETS), agriculture and waste (non-ETS sector) is the responsibility of the member states, which have committed themselves under the EU Climate Change Regulation to adhere to contingent annual budgets for $\mathrm{CO} 2$ emissions.

On 21 April 2021, the European Parliament and the Council of the European Union agreed on a new greenhouse gas emission reduction target for 2030. The goal is to reduce $\mathrm{CO} 2$ emissions by 55 percent by 2030 
compared to the reference year 1990. In addition to a tightening of the 2030 target, the climate law now agreed for the EU stipulates climate neutrality by 2050 . This means that by that time no more $\mathrm{CO} 2$ emissions may be emitted than can be removed from the atmosphere by natural or technical processes [8].

Since the revision of the European climate and energy policy legislation in Germany, a new "Fit for 55" package has been presented. The aim is to reduce greenhouse gas emissions by at least $55 \%$ by 2030 compared to 1990 levels [9]. This demand is also in line with the ruling of the German Federal Constitutional Court of 29 April 2021, which calls on the legislator to observe intergenerational justice and not to postpone necessary emission reductions. In order to comply with this ruling and the Paris Climate Agreement, it is crucial that the "Fit for 55" package enables emission reductions beyond 55 percent. Only a really good climate concept can contribute to the goal, which is why energy management is essential in every possible sector. Without compliance, penalties for individual member states will follow. The European Union's target has been tightened by the new legislation, because only with the help of all member states will the ambitious targets be met and thus the environment protected.

These targets are an important driving force for technical innovations in energy management.

\section{Aim of implementing an en- ergy management system}

\subsection{Creat incentives}

In order to achieve the goal of efficient energy management, future plants have to be planned according to the requirements and existing plants must be modernised, if necessary from the ground up. Directives, laws, and standards primarily determine the behaviour of society and industry with re- gard to access to electronic energy and energy consumption. Legal requirements are obligations and must therefore be respected and complied with. At the same time, however, incentives are created that have a motivating influence to possibly invest in a future-oriented manner beyond the legal basis. This means that digital evaluation, visualisation and storage of measurement data should take place in the area of energy management. With the right components, energy savings, cost savings, quality of supply, security of supply and energy efficiency can be guaranteed.

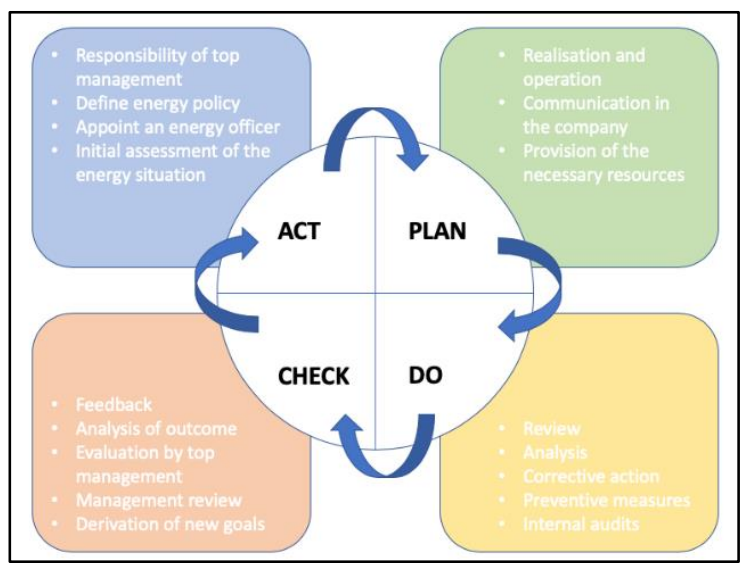

Fig. 1: Definition of PDCA-Cycle

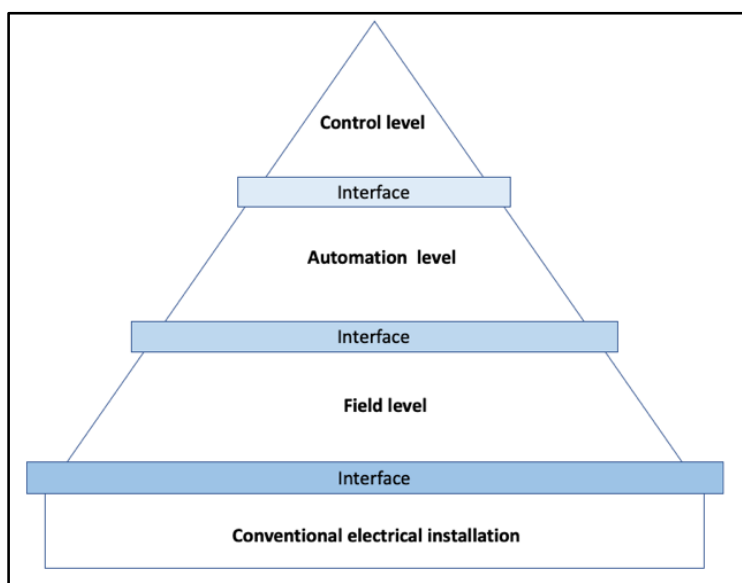

Fig. 2: Example of an energy management pyramid

This illustration shows an example of how an energy management system can be im-

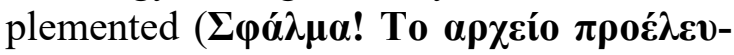




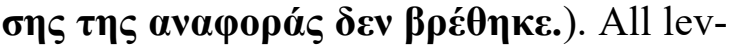
els from management to field level are brought together in one flow. Data for energy monitoring can be recorded using energy measuring components such as a communication-capable measuring device, a circuit breaker, a soft starter, a frequency converter or a motor. Furthermore, processing and visualisation are possible with the help of a PLC and a human machine interface. Data selection and evaluation can be realised with the help of software at the management level. There are many different application possibilities for implementing energy management, but the management level, the production level and the field level should be taken into account as a guide. As an additional option, the data can be uploaded to a cloud, which allows access from many different locations. The investments should be in the area of communicationcapable measuring devices with a wide range of measuring possibilities, the energy management software as well as the specialised personnel. As a result, energy monitoring is necessary. The continuous evaluation and recording of relevant measurement data helps, for example, to reduce the effort required for the prescribed regulations and logged energy measurement data.

\subsection{GUIDELINES FOR IMPLEMENTA- TION}

To implement these goals, the following important guidelines and laws have been issued or are currently being adapted as you can see in Table 1. The table lists the European Union directives that must be transposed into national law. As mentioned above, implementation is mandatory for each member state.

EU

Energy Services Directive (ESD) of 2006 (Directive 2012/27/EU of 25 October 2012) [7]

Eco-design Directive and Energy Using Products Act (EuP Directive) (Directive 2009/125/EC of 21

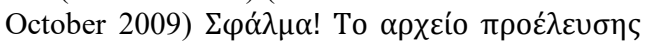

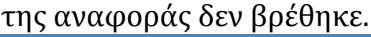

Emissions allowance trading DIRECTIVE 2003/87/EC OF THE EUROPEAN PARLIAMENT AND OF THE COUNCIL of 13 Oc-

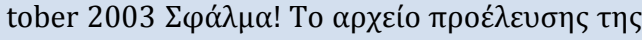

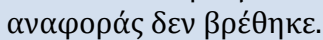

Building Efficiency Directive (EU) 2018/ 844 of

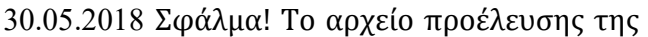
$\alpha \nu \alpha \varphi \circ \rho \alpha \dot{\varsigma} \delta \varepsilon v \beta \rho \varepsilon \dot{\theta} \eta \kappa \varepsilon$.

Energy Efficiency Directive (EED Directive 2018/2002 of 11.12.2018) [5]

Table 1: Basic rules for implementation of energy management

The main objectives of the Energy Services Directive (ESD) of 2006 (Directive 2012/27/EU of 25 October 2012) are to set energy efficiency targets. In addition, the mandatory energy savings of the EU member states are set. The focus is on regular energy audits and cost-benefit analyses for new buildings or modernisation. The desired results of the Energy Efficiency Directive are, among others, the reduction of energy costs through lower consumption, climate protection through the reduction of energy consumption and incentives for investments in the economic sector [10].

The aim of the Ecodesign Directive is therefore to improve the environmental performance of energy-related products, taking into account their entire life cycle, by setting ecodesign requirements. To this end, it sets minimum requirements for product design. In addition, there will also be new energy labels from 1 March 2021. The current classification from $\mathrm{G}$ to $\mathrm{A}+++$ will be changed to a scale from $A$ to $G$ (the plus signs will be dropped). The measures of the Ecodesign Directive offer benefits by reducing energy costs in Europe through energy savings and by reducing greenhouse gas emissions. In this way, they make a direct contribution to the implementation of the Paris Agreement on climate protection and give an impetus to more circular econ-

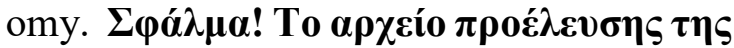

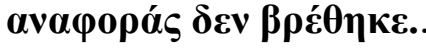

Emissions trading within the European Union, also known as ETS, is an instrument for 
reducing greenhouse gas emissions at the lowest possible cost. The Emissions Trading Directive applies primarily to large industries in the sectors of energy conversion and transformation, production and processing of ferrous metals, and the paper and pulp industries. It thus covers almost half of EU-wide greenhouse gas emissions.

The aim of the directive is to work towards reducing greenhouse gas emissions in the most cost-effective and economically acceptable way possible through an emissions

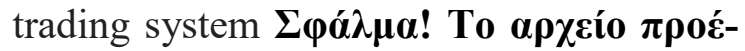

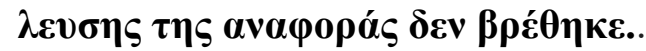

The Building Energy Performance Directive aims to improve the energy performance of buildings in the European Union (EU), taking into account different climatic and local conditions.

The amending Directive (EU) 2018/844 requires EU countries to develop long-term renovation strategies to promote the renovation of residential and non-residential buildings in order to achieve a highly energy-efficient and decarbonised building stock by 2050.

With the help of information and communication technology as well as intelligent automation and control technologies in buildings, implementation is to be facilitated. In addition, the expansion of the infrastructure for charging electric vehicles in building parking lots should be supported, because the intelligence factor of the grid should be increased through smart grids and micro grids. This in turn helps to ensure energy efficiency through optimised adaptation to the

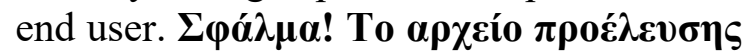

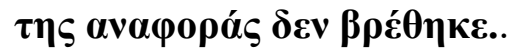

With the Energy Efficiency Directive, the EU states have committed themselves to reducing the energy consumption of real estate. Residents are to be encouraged to use resources such as heating energy or water more consciously through greater transparency of consumption. The overall goal of the directive is to reduce energy consumption in the EU by 32.5 percent by 2030 compared to the consumption forecast in 2007. In addition, the member states have committed themselves to annual savings of 0.8 percent [5].

Energy management and the promotion of additional energy storage technologies offer the potential to make optimal use of additional energy sources and to reduce energy demand. The implementation of energy efficiency measures also contributes to independence from energy imports. The introduction of an energy management system should help to determine the exact energy consumption of a company and show possibilities to save resources such as electricity, heating and water. The introduction of an energy management system is not just a one-time assessment and inventory control but must be repeated continuously in cycles. The measures have to be carefully planned - in relation to the respective company/organisation - regularly monitored and the data collected and compared.

\subsection{IMPLEMENTATION OF ENER- GYMANAGMENT SYSTEM}

\subsubsection{Virtual machine resource allocation for energy-efficient cloud data cen- tres}

Cloud computing has become increasingly important in recent years. The advantages for small and medium-sized enterprises include cost savings and flexible collaboration, but on the other hand there are major challenges such as power consumption. Data centres (RZ) are used for administrative tasks, administration, data processing and data storage. However, data centres require a lot of energy and are therefore criticised, even though the share of virtual to physical servers has shrunk. Following the publication of the Energy Watch Manager in 2019 [14] shows that data centres account for $4.7 \%$ of annual electricity consumption 
worldwide. Because of this, power consumption is optimised with the help of a dynamic method with intelligent operation. This is to be achieved by reducing inactive resources, increasing virtualisation technologies and switching off inactive components. [2]. This realisation is essential for energy management, as in this case the interfaces between control level and automation level are optimised. In each level of the energy management pyramid, the optimisation of efficiency plays a decisive role, since here, too, action must be taken according to the PDCA cycle.

\subsubsection{Energy management in the manu- facturing industry}

The use of photovoltaics, energy storage, CHPs and wind turbines, for example, offers a company the opportunity to compensate for its own energy consumption with renewable energies and at the same time reduce its $\mathrm{CO}_{2}$ footprint. However, the energy-generating components must be connected to each other by an intelligent network, with software taking over the control of the energy distribution. The surplus energy that is ideally produced during the day by photovoltaic systems and wind turbines and is not needed for production should be stored in energy reservoirs for the low-energy hours at night. Not only energy days, but also energy peaks in production can be intercepted by the available energies of the storage units, thus reducing the load on the power grid and the costs for peak loads. This means that not only the power lines are spared, but also the company's financial budget. In addition, the $\mathrm{CO}_{2}$ footprint is also reduced by the energy management measures, bringing the goal of "zero emissions" ever closer. Energy management is becoming increasingly complex due to the different areas of energy production. Thus, the system grows more and more and results in a monitored energy flow as it can be seen in the abstract in Figure 2. The management takes place on different levels, which are connected via interfaces [15] [16].

\subsubsection{SENTRON 3VA2 compact circuit- breaker}

Compliance with the regulations for valuable energy monitoring of energy data such as current, voltage, power, phase position would be realisable with a commercial measuring device and current transformer. In an existing installation, there may be a lack of space in the energy distribution system, making it impossible to implement a suitable and compliant energy management system on site.

For such challenges, the $3 \mathrm{VA} 2$ compact circuit-breaker offers a space-saving and optimal solution. The flexible communication options via Profinet, Profibus, Modbus TCP and Modbus RTU provide a high level of transparency.

By reporting the system statuses and measured values to higher-level management systems, the system utilisation can be optimised, savings potential can be identified and energy efficiency can be increased (transparency of the status of the energy distribution and its energy flows). The 3VA2 compact circuit-breaker can thus support the company's energy management.

The energy operating data, service and maintenance information from the switch are read out and projected on a human machine interface. In addition, the data is stored e.g. via an internal memory of the human machine interface, which, depending on the setting, is evaluated after one working day with the help of a program on the computer and then made available to the person responsible for energy management for further processing. Relevant energy data include, as already mentioned above, current, voltage, active line, apparent power, current frequency, fundamental oscillation power factor; service and maintenance information includes, for example, the number of trips (due to a fault), mechanical clearances and the reason for the last trip. A circuit breaker is used in almost every industrial building today. If the company is willing to use an energy management system, the communication-capable compact 
circuit-breaker helps to record all relevant data for an energy management system right from the field level. The recorded data is then evaluated with a programme and compared with the previous measurement data according to the PDCA cycle in order to have reached the target agreement after successful measures. A communication-enabled component such as the compact circuit-breaker is an entry point for companies that are obliged to operate an energy management system or do so voluntarily. An extension with energy-efficient and data-reporting loads or further compact circuitbreakers and PLCs then provides energy management at all levels of the automation pyramid [17]. The switch itself is located in the field level.

\subsubsection{SIRIUS 3RW55 soft starter}

The SIRIUS 3RW55 soft starter allows the starting current and the starting torque to be limited; it is adapted to the load behaviour of the driven machine by continuously controlling the voltage.

The mechanical load on the operating equipment is kept particularly low by the gentle acceleration, thus extending the service life.

The added value of the communication-capable 3RW55 soft starter for energy management is that the measured values and diagnostics are forwarded to a higher-level PLC and an evaluation of the warnings and operating statuses is possible. The most important prerequisite for successful energy monitoring is data storage, which is realised with the help of a PLC, for example.

The energy flow of the entire automation pyramid is mapped by communication-capable components in the conventional electric installation. The energy consumption and the energy generation, if possible by regenerative power supply, are tracked by monitoring. The soft starter is used, for example, in agitators, centrifuges, stone crushers and conveyor belts and creates transparency through the last instance of the energy flow. Digitisable, communication-enabled components complete an energy management system and enable continuous optimisation by controlling (Check; Act) the energy values [18].

\section{IMPLEMENTATION OF THE REGULATORY MEASURES}

\subsection{DiRECTIVES AND REgUlations AS REGULATORY INSTRIMENT}

The directives and regulations provide a framework of requirements that must be followed and implemented for the climate policy goals. The implementation of directives is a binding legal act for all member states of the European Union. The directives set by the EU give the member states a target to be achieved, but it is up to the countries to realise the target with their own legislation. It is clear from section 2 Legal frameworkwork for the enforcement of energy efficiency and the examples in section $3.3 \mathrm{Im}$ plementation of energy management that the regulatory measures lay the foundation and create the incentives for achieving the energy policy goals. Furthermore, the standards "complement/expand" the basis for the management of energy resources; thus, a complement is an enrichment for the achievement of the targets.

\subsection{FOCUS ON ENERGYMANAGEMENT}

As explained in the examples in section 3, energy management plays a key role at every level of the system. Therefore, it is of vital importance to set energy management even more discreetly in the focus for achieving climate policy goals. The DIN EN ISO 50001 standard can make a considerable contribution here. The standard describes application mechanisms and aids for optimisation processes. An energy management system (EnMS) according to ISO 50001 can be implemented independently of existing management systems or integrated into existing management systems. 
DIN EN ISO 50001 defines requirements and instructions for the introduction, implementation, maintenance and improvement with the aim of enabling an organisation to achieve energy saving potentials through continuous improvement of energy-related performance and thus help to reduce energy costs, greenhouse gases and other environmental risks.

With the increasing international significance of the topic of energy efficiency, the standards organisation ISO has issued further standards in the 50000 series. ISO 50002:2014 describes the requirements for an energy audit and will presumably replace DIN EN 16247 in the future. With ISO 50003:2014 "Energy management systems - Requirements for bodies providing audit and certification of energy management systems", an international set of rules for certification bodies was published. ISO 50003 specifies how and to what extent energy management systems are to be certified. In future, the duration of an audit will be determined by the energy sources used, the energy consumption and the complexity of a company. A certificate is only to be issued upon proof of continuous improvement of energy-related performance. Support for an energy audit is provided by the ISO 50006 guidelines.

\section{Conclusion}

Efficiency and savings in the field of energy play a key role today and in the future. With the trend towards renewable energies, the legislative and directive process is being intensified by the European Union in order to save energy. If a company uses the optimal components for an energy monitoring system, a basis is created for operational energy management in accordance with ISO 50001. With maximum plant safety, highest plant availability, short amortisation time of the required equipment, permanent cost reduction (energy savings with plant and cost savings) through e.g. avoidance of financial sanctions such as fines, the company benefits in many ways. However, the optimum can only be achieved with a constantly individually adapted energy management system; this means that a review of the systems takes place at short intervals in order to offer continuous improvement.

This means that, as described above in section 2.2 Energy management according to ISO 50001 in connection with the PDCA cycle subsection, energy management through the applied cycle (PDCA) is extracted at short, time-defined intervals by the responsible employee in cooperation with top management, the differences between planned and actual results are extracted and further procedures for optimisation are determined. The implementation of an energy monitoring system is of fundamental importance in the context of the energy audit, but especially in the context of an energy management system. In summary, it can be stated that with EN16247, ISO 50001:2011-12 and its successor ISO 50001:2018, a global standard is available that sustainably supports organisations/companies in driving energy efficiency measures forward. The next work will relate to the international and European standards, examining the relationship between the standards and their impact on energy management. In addition, an investigation of the implementation of the European directives and regulations into national German law will be undertaken in the near future. [19]

Energy management (not the energy management system according to ISO 50001) should generally be more in focus at the European level, because the directives and regulations do not cover the areas that are needed for a targeted approach. In addition, there are also standards at the European level (DIN EN 16247-1), which were not discussed here, but which once again show how important it is that resource management takes place. 
This is underlined once again by the decision of individual countries such as Germany. Germany is discussing "stricter targets" until 2045 , because by then the goal is to be climate neutral. [20]. This means that Germany is already aiming for the climate protection target 5 years before the actual "zero emission". In future, the regulatory measures should be better coordinated with the standards in order to create a symbiosis of obligations and instruments for successful application.

\section{Acknowledgement}

I would like to thank my supervisor Prof. Dr. Petr Mastny for his constructive criticism and advice, VUT Brno and my family for their support during the preparation of this publication. It is nice to know that you always fall into loving arms that catch you when you need them. Thank you!

\section{References:}

[1] Ashwani Kumar, V. M. Mishra, Rakesh Ranjan, A Survey on Hybrid Renewable Energy System for Standalone and Grid Connected Applications: Types, Storage Options, Trends for Research and Control Strategies, WSEAS Transactions on Electronics, ISSN / E-ISSN: 1109-9445 / 2415-1513, Volume 11, 2020, Art. \#10, pp. $80-85$.

[2] Ogechukwu M. Okonor, Mo Adda, Alex Gegov, Intelligent Agent-based Technique for Virtual Machine Resource Allocation for Energy-Efficient Cloud Data Centres, WSEAS Transactions on Communications, ISSN / E-ISSN: 1109-2742 / 2224-2864, Volume 19, 2020, Art. \#5, pp. 37-46.

[3] European Commission (2017): 2030 climate \& energy framework. 2030 climate and energy framework- existing ambi- tion. https://ec.europa.eu/clima/policies/strategies/2030_en - European Commission - 16.01.2021.

[4] Official Journal of the European Union (21.12.2018): DIRECTIVE (EU) 2018/2001 OF THE EUROPEAN PARLIAMENT AND OF THE COUNCIL, https://eur-lex.europa.eu/legal-content/EN/TXT/PDF/?uri=CELEX:32018 L2001\& from=DE - EUR-Lex Access to European Union law 07.01.2021.

[5] Official Journal of the European Union (21.12.2018): DIRECTIVE (EU) 2018/2002 OF THE EUROPEAN PARLIAMENT AND OF THE COUNCIL, https://eur-lex.europa.eu/legal-content/EN/TXT/PDF/?uri=CELEX:32018 L2002\& from=EN - EUR-Lex Access to European Union law 07.01.2021.

[6] Official Journal of the European Union (21.12.2018): REGULATION (EU) 2018/1999 OF THE EUROPEAN PARLIAMENT AND OF THE COUNCIL, https://eur-lex.europa.eu/legal-content/EN/TXT/PDF/?uri=CELEX:32018 R1999\&from=EN - EUR-Lex Access to European Union law 07.01.2021.

[7] Usman I., Windijarto, Developing green operations to minimize energy consumption by pdca cycle of ISO 50001. A case study with Delphi method approach, Journal of Security and Sustainability Issues, ISSN 20297017, DOI 10.9770/JSSI.2020.9.M(34), Volume 9, 2020, pp. 451-459, 30.06.2021

[8] European Commission, Energy, Climate change, Environment, Climate Action, EU Action, Climate strategies \& targets, 2030 climate \& energy framework, https://ec.europa.eu/clima/policies/strategies/2030_en 21.01.2021

[9] WELT, Ausland, Minus 55 Prozent, Einigung auf EU-Klimaziele für 2030, 21.04.202, https://www.welt.de/politik/ausland/article230547879/Minus-55Prozent-Einigung-auf-EU-Klimazielfuer-2030.html, 01.07.2021 
[10] Official Journal of the European Union (14.11.2012): DIRECTIVE 2012/27/EU OF THE EUROPEAN PARLIAMENT AND OF THE COUNCIL of 25 October on energy efficiency, amending Directives 2009/125/EC and 2012/30/EU and repealing Directives 2004/8/EC and 2006/32/EC https://eur-lex.europa.eu/legal-content/en/TXT/?uri=CELEX\%3A32012L0 027 - pp. L351/1 EUR-Lex Access to European Union law 02.01.2020

[11] Official Journal of the European Union (14.11.2012): DIRECTIVE 2009/125/EC OF THE EUROPEAN PARLIAMENT AND OF THE COUNCIL of 21 October 2009 establishing a framework for the setting of ecodesign requirements for energy-related products. https://eur-lex.europa.eu/legal-content/EN/TXT/PDF/?uri=CELEX:32009 L0125\& from $=$ EN 02.01.2020

[12] Official Journal of the European Union (14.11.2012): DIRECTIVE 2003/87/EC OF THE EUROPEAN PARLIAMENT AND OF THE COUNCIL of 13 October 2003 establishing a scheme for greenhouse das emission allowance trading within the Community and amending Council Directive 96/61/EC https://eurlex.europa.eu/legal-content/EN/TXT/PDF/?uri=CELEX:32009 L0125\&from $=$ EN 02.01.2020

[13] Official Journal of the European Union (19.06.2018): DIRECTIVE (EU) 2018/844 OF THE EUROPEAN PARLIAMENT AND OF THE COUNCIL of

[19] Business Insider Deutschland, Neue Klimaziele für Deutschland: 65 Prozent weniger $\mathrm{CO}_{2}$ bis 2030 - und klimaneutral 2045, Home Politik Deutschland, 05. Mai 2021, https.//www.businessinsider.de/politik/deutschland/neu-klima30 May 2018 amending Directive 2010/31/EU on the energy performance of buildings and Directive 2012/27/EU on energy efficiency, L156/75. https://eur-lex.europa.eu/legal-content/EN/TXT/PDF/?uri=CELEX:32018 L0844\&from=IT 02.02.2021
[14] OgechukwuOkonor, Mo Adda" Power Optimisation Model for Leveraging Cloud System”, IEEE Conference, 2019. 01.07.2021

[15] Hesham M. Enshasy, Qasem Abu AlHaija, Hasan Al-Amri, Mohamed AlNashri, Sultan Al-Muhaisen, Mashhour Al-Tarayrah, A Comprehensive Construction of Hydrogen-Hydrogen-Oxygen (HHO) Cell as Renewable Energy Storage, WSEAS Transactions on Systems, ISSN / E-ISSN: 1109-2777 / $2224-$ 2678, Volume 19, 2020, Art. \#17, pp. 121-132. 01.07.2021

[16] Jihane Kartite, Mohamed Cherkaoui, Backtracking Search Algorithm for Total Cost Optimization of Hybrid Renewable PV/Wind System Coupled with Battery Storage, WSEAS Transactions on Systems, ISSN / E-ISSN: 1109-2777 / 22242678, Volume 19, 2020, Art. \#8, pp. 5561. 01.07.2021

[17] Information of own investigation from the bachelor-thesis „SENTRON Kompaktleistungsschalter 3VA2" -Einsatz in der Industrie 4.0 - Carina Beermann 01.08 .2017

[18] Information of own investigation from the bachelor-thesis ,SIRIUS soft starter 3RW55 - analysis of measured values to increase sustainability- Carina Beermann 01.08 .2017

ziele-fuer-deutschland-65-prozent-weniger-co2-bis-2030-und klimaneutral2045/, online: 10.06.2021

[20] Bundesregierung, Klimaschutz, Klimaschutzgesetz 2021, Generationenvertrag für das Klima, https://www.bundesregierung.de/breg-de/themen/klimaschutz/klimaschutzgesetz-2021-1913672, online: 01.07.2021

\section{Creative Commons Attribution License 4.0 (Attribution 4.0 International, CC BY 4.0)}

This article is published under the terms of the Creative Commons Attribution License 4.0 https://creativecommons.org/licenses/by/4.0/deed.en_US 